\title{
Konya Bölgesinde Çocuk Yanıkları ve Özellikleri
}

\author{
Pediatric Burns and Characteristics in Konya Region
}

Metin GÜNDÜZ ${ }^{1}$

\author{
1. Selçuk Üniversitesi Tıp Fakültesi Çocuk Cerrahisi Anabilim Dalı, Konya
}

\section{ÖZET}

Amaç: Yanık ünitesinde tek hekim tarafindan tedavi edilen çocuk hastaların özelliklerini değerlendirmek.

Gereç ve Yöntemler: Konya Ĕgitim ve Araştırma Hastanesi Yanık Ünitesi'nde Eyül 2013- Nisan 2014 arasinda tek hekim tarafindan tedavi edilen hastaların dosyalart retrospektif olarak tarandi.

Bulgular: 48 hastanın 26 'sı erkek 22 'si klz olup yaş ortalamas 3.1 bulundu. Hastalartn \% 48 'inde 2. derece yüzeyel \% 48 'inde 2. derece derin ve \% 4'ünde 3. derece yanık mevcut olup total yanı yüzeyi ortalaması \% 8 bulundu. Yanık etkenleri çay \% 44, sicak su $\% 36$, soba $\% 8$, süt $\% 2$, yağ $\% 2$, düdüklü tencere patlamast $\% 2$, jel alevlenmesi $\% 2$, parfüm alevlenmesi $\% 2$, ve bomba patlamasi $\% 2$ idi. Tedavide 11 hastaya debritmanı yapıld, 4 hastaya greft uyguland, 1 hastaya eskarotomi yapılıp üst merkeze sevk edildi, 2 hasta basi giysisi kulland ve 6 hasta aile isteğiyle taburcu edildi.

Sonuç: Olguların \% 80'i haşlanma yaniğl olup etken genelde çay içme alışkanlığldır. Çocuklar kendilerini koruyamayacak yaşta olduklarından ebeveynler gerekli önlemler konusunda bilgilendirilmelidir. Minor ve moderate yanıkların tedavisi için yanık ünitelerindeki hekim ve hemşireler meslek içi eğitim almalıdır.

Anahtar Kelimeler: çocuk; yanık; haşlanma

\section{ABSTRACT}

Objective: We evaluated the etiology factors ant treatment modalities of pediatric burns.

Material and Methods: This retrospective study was carried out using data from Konya Education and Research Hospital Burn Unit. Patients those admitted to our hopital between September 2013 - April 2014 were evaluated.

Results: Clinical data, including age and sex of the patient, depth of burn injury, TBSA (total body surface area) burned \%, etiology of burn and treatement were evaluated. The 48 study subjects included $26(\% 54)$ male and $22(\% 46)$ female pediatric patients (mean age, 3.1 years 1-17). \%38 percent of patients had second degree superficial, $\% 48$ of them had had second degree deep and $\% 2$ had third degree burns. The mean percentage of TBSA was $\% 8$ (\%3-55). Etiology of burn was tea $\% 44$, hot water $\% 36$, stove $\% 8$, milk $\% 2$, oil $\% 2$ scent bottle $\% 2$, pressure cooker explosion $\% 2$, gel candles $\% 2$, and bomb $\% 2.11$ of 48 patients (\%23) had wound debridement under general anestesia, $4(\% 8.3)$ patient were treated by autogrefting, parents of 6 patient refused treatment, 2 patients used pressure dresing, and after escarotomy 1 patient was transferred to burn center.

Conclusion: In \%80 of patients etiology is scalding. Most of them ocur due to tea. Parents must be educated. Vocational Training of pediatric surgeons and nurses is necessary for treating minor and moderate burn.

Keywords: child; burn; scald

\footnotetext{
İletişim Bilgileri

Sorumlu Yazar: Yard. Doç. Dr. Metin GÜNDÜZ

Yazışma Adresi: Selçuk Üniversitesi Tıp Fakültesi, Çocuk Cerrahi Anabilim Dalı, 42131, Selçuklu, Konya

E-posta: drmetingunduz@yahoo.com

Tel: +90 (533) 4187467 İş: +90 (332) 2244511

Makale Geliş Tarihi: 26.12.2016

Makale Kabul Tarihi: 03.04.2017

DOI: http://dx.doi.org/10.16948/zktipb.281504
}

\section{GíRIS}

Deri vücuttaki en büyük organ olup epidermis ve dermisten oluşmaktadır. Sıv1-elektrolit kayb1, enfeksiyon ve radyasyona karşı korunma sağlamakla birlikte termal regülasyonu sağlar. Yanık; epidermis ve dermisin bir kısmı veya tamamının nekrozuyla sonuçlanan çoğunlukla 1sı teması sonucu oluşan yüksek mortalite ve morbiditeye sahip travmadir (1). $\mathrm{Bu}$ travmanın oluşumunda etnik, kültürel ve çevresel faktörlerin etkili olduğu bildirilmiştir (2). Yaş, cinsiyet, yanık nedeni, yanık yüzey ve derinliği mortalite ve morbiditede belirleyicidir (3). Yanığın şiddetine göre tedavi edilebileceği sağllk birimleri, ülkemizde 2012 y1lında Sağlık Bakanlığı tarafindan yayınlanan yanık yaralanmaları tedavi algoritmasına göre poliklinik, yanık odas1, yanık ünitesi veya yanık tedavi merkezidir (4). Bu çalışmada yanık ünitesinde tek hekim tarafından tedavi edilen çocuk hastaların yanık etkenleri ve tedavi özellikleri incelendi.

\section{GEREÇ ve YÖNTEM}

Konya Eğitim ve Araştırma Hastanesi Yanik Ünitesi'nde Eyül 2013 - Nisan 2014 arasında tek hekim tarafından tedavi edilen çocuk yanık hastalarının dosyaları retrospektif olarak tarand1. Hastalarda yaş, cinsiyet, yanık derinliği, total yanık yüzeyi (TYY) \%, yanık etkenleri ve uygulanan tedavi değerlendirildi. Yanık Ünitesi 13 yataklı olup hem erişkin hem de çocuk hastalara hizmet vermektedir. Çalışmayı yapan hekim ile birlikte ünitede görevli sağlik personelinin bir kısmı da değişik zamanlarda Ankara Çocuk Sağlığı ve Hastalıkları Hematoloji Onkoloji Eğitim ve Araştırma Hastanesi ve Ankara Numune Hastanesi Yanık Merkezi'nde eğitim almışlardır.

\section{BULGULAR}

48 hastanın 26's1 (\% 54) erkek, 22'si (\% 46) kız olup yaş ortalaması 3.1'di. Hastaların $\% 48$ 'inde 2 . derece yüzeyel $\% 48$ 'inde 2 . derece derin ve $\% 4$ 'ünde 3 . derece yanık mevcut olup total yanık yüzeyi ortalaması $\% 8$ olarak bulundu. Yanık etkenleri çay \% 44, sicak su $\% 36$ (Resim 1- a), sobaya temas \% 8, süt \% 2 , yağ $\% 2$, düdüklü tencere patlaması $\% 2$, 
jel alevlenmesi \% 2, parfüm alevlenmesi \% 2 ve bomba patlamas $1 \% 2$ idi (Sekil 1). Tedavide 11 hastaya debritmanı yapıld1, 4 hastaya greft uyguland1 (Resim 1- b), 1 hastaya eskarotomi yapılıp üst merkeze sevk edildi, 2 hasta hipertrofik skar (Resim 1- c) nedeniyle bası giysisi kulland1 (Resim 1-d) ve 6 hasta aile isteğiyle taburcu edildi. 24 hasta ise bacitrasin-neomisin sülfat pomad, gümüş sülfadiazin krem, \% 5 klorheksidin emdirilmiş gazlı bez ve gümüşlü hidrofiber yara örüsü ile pansuman yapılarak tedavi edildi.

\section{TARTIŞMA}

Çocuk hasta grubunda yanık önemli bir sorundur. Yaș ortalamasının düşüklüğü değerlendirildiğinde ebeveynlerin bu konudaki dikkatsizliği, eğitimsizliği, hatta ihmali olduğu ortaya çıkmaktadır. Yanık nedeniyle hastaneye başvuruların yarısını çocuk hastalar oluştur- makta olup bunlarda yaş azaldıkça mortalite artmaktadır (3). Doğal afetler nedeniyle olușan yanıklar engellenemese de kazaların oluşumu bazı önlemler ile azaltılabilir. Türkiye'de çocuk yanıkları genelde ev içerisinde olmakta olup en sık nedeni haşlanma yanıklarıdır (5).

Erișkin hastalarda ise ilk sırayı alev yanıkları almaktadır (6). Yöresel faktörler yanık etyolojisinde belirleyici etkiye sahiptir. Doğu Akdeniz bölgesindeki yanıklı çocukların epidemiyolojik özelliklerini inceleyen retrospektif bir araştırmada haşlanma yanıkları ilk sırada olup alt türde süt ve yöresel tarhana yapımında kullanılan dövme buğdayın haşlanması sırasında oluşan yanıklar yer almaktadır. Çalışmamizdan farklı olarak etkenler arasında tandira düşme, elektrik yanıkları, TYY \% 13 bulunmas1 ile tedavide ilk 3 gün tüm hastalara gümüș sülfadiazin uygulanması ve greft uygulanmas1na yönelik bilgi olmaması yer almaktadır (7).

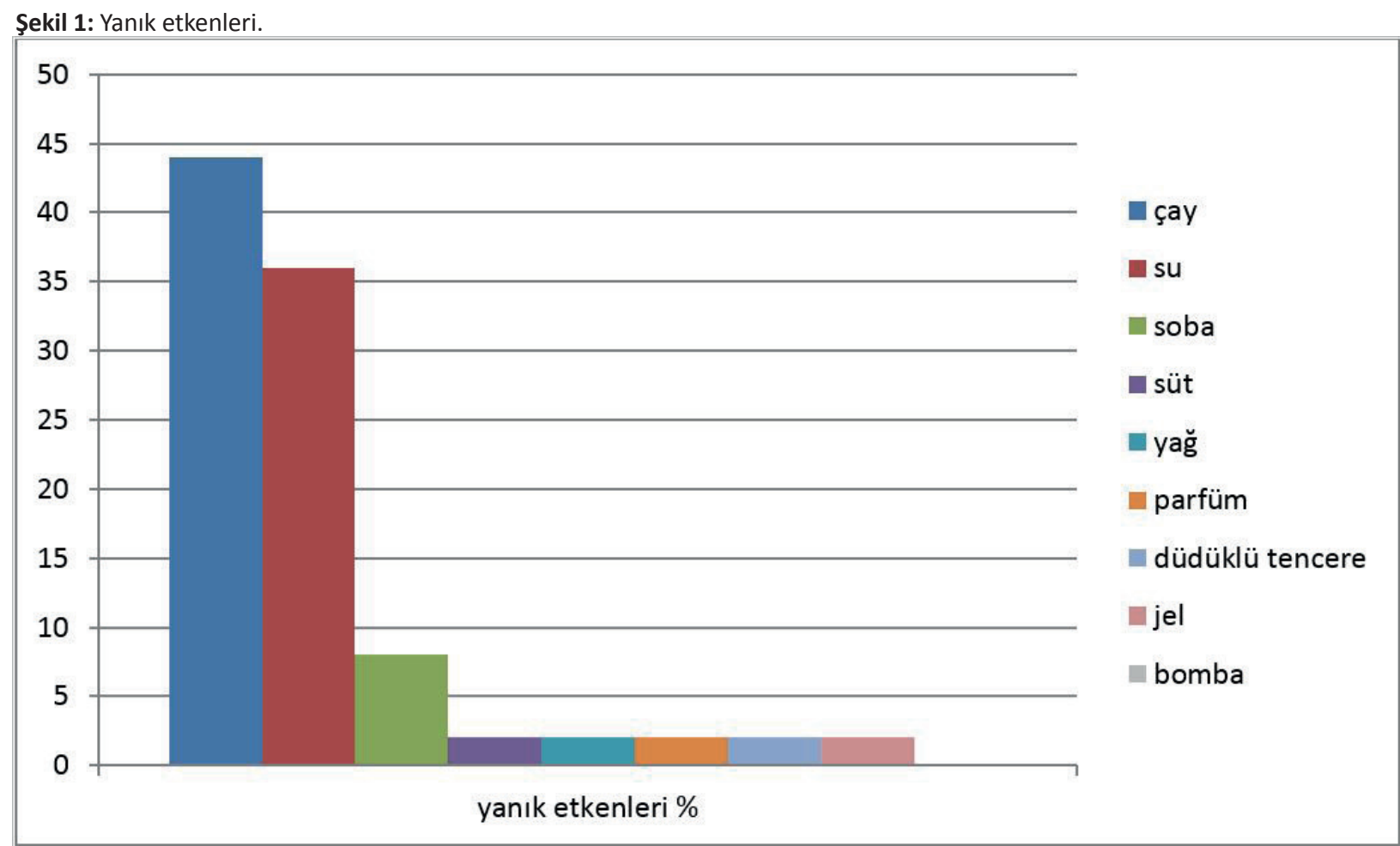

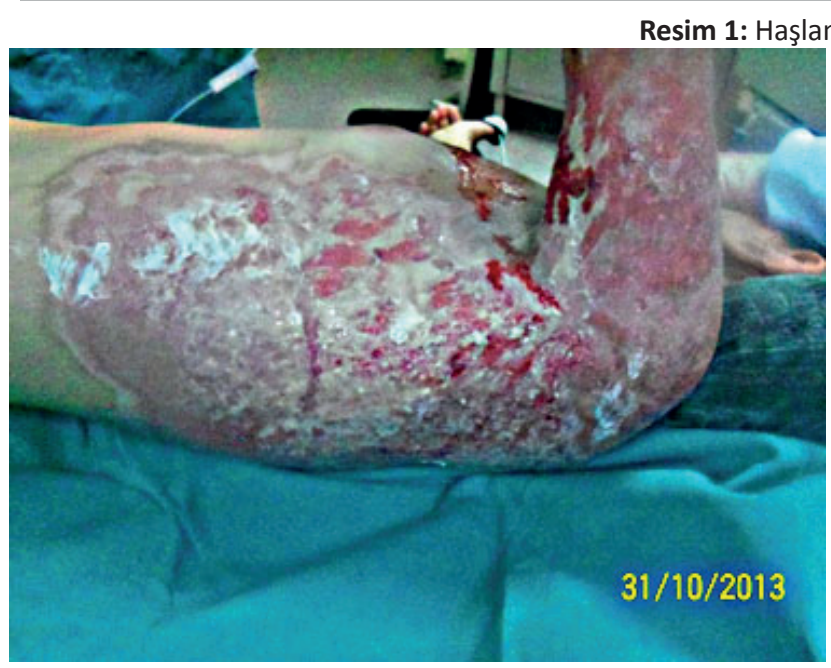

a) Enfekte.

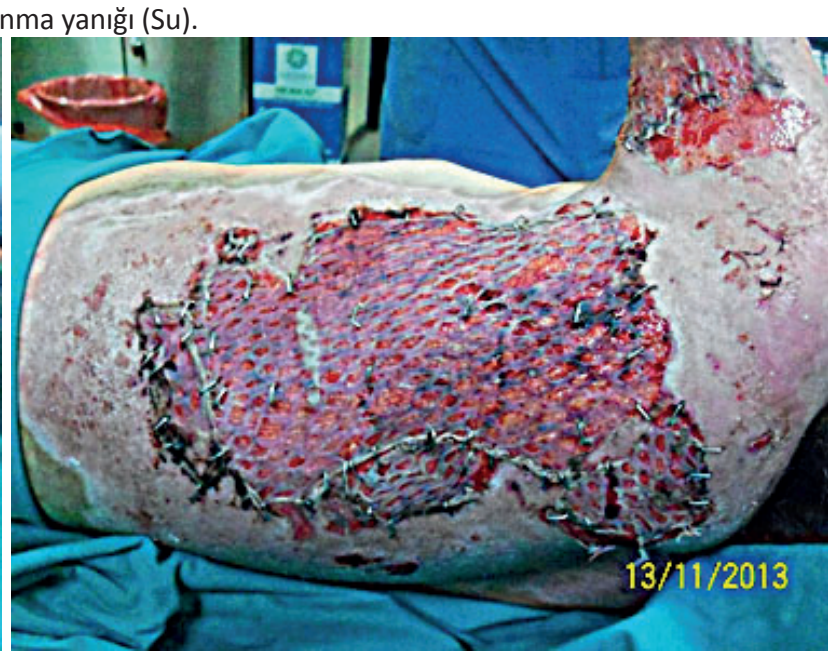

b) Debritman sonrası greft. 
Güzel ve ark.'nın Trakya Üniversitesi'nde haşlanma yanıklarının karakteristik özelliklerini tanımlamak için yaptığı çalışmasında sıcak su ile haşlanma çocuklarda en sık yanık etkeni olarak belirtilmiștir. TYY \% 10 olarak belirtilmiş fakat farkli olarak tedavi-takip bilgileri yetersizdir (8). Sakallığlu ve ark.'nın Ankara, Adana ve Konya Bölgesini kapsayan çalıșmasinda sicak su ile haşlanma en sik etken olarak bulunmuștur (9).

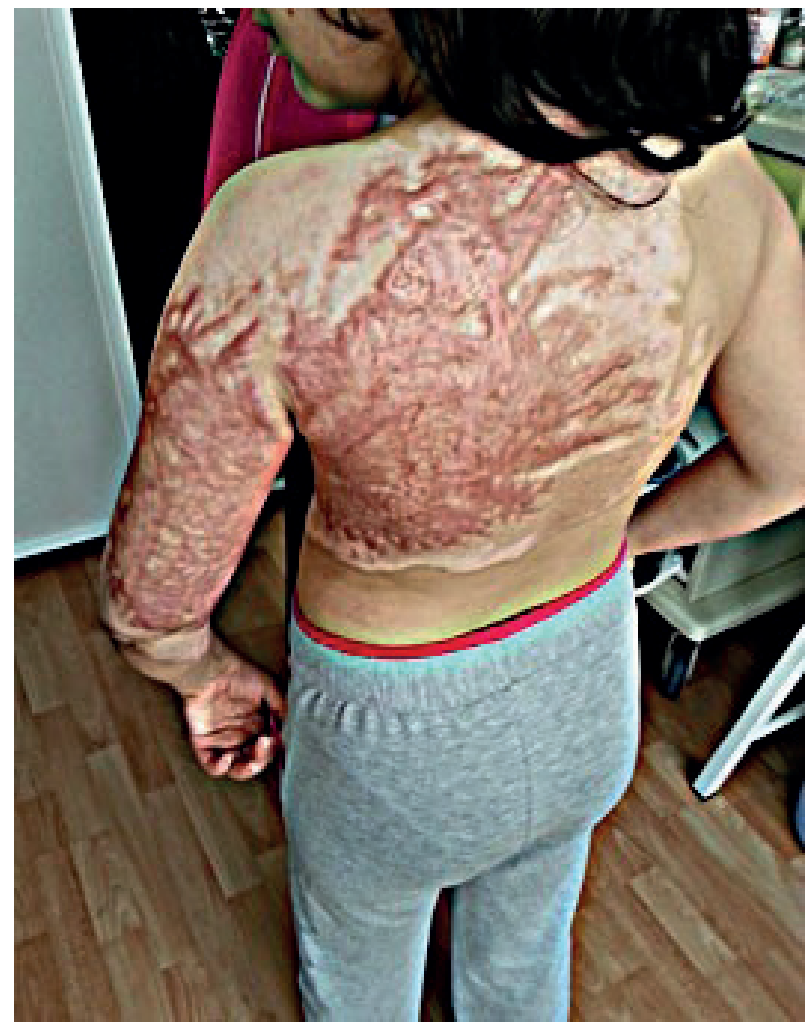

c) Hipertrofik skar.

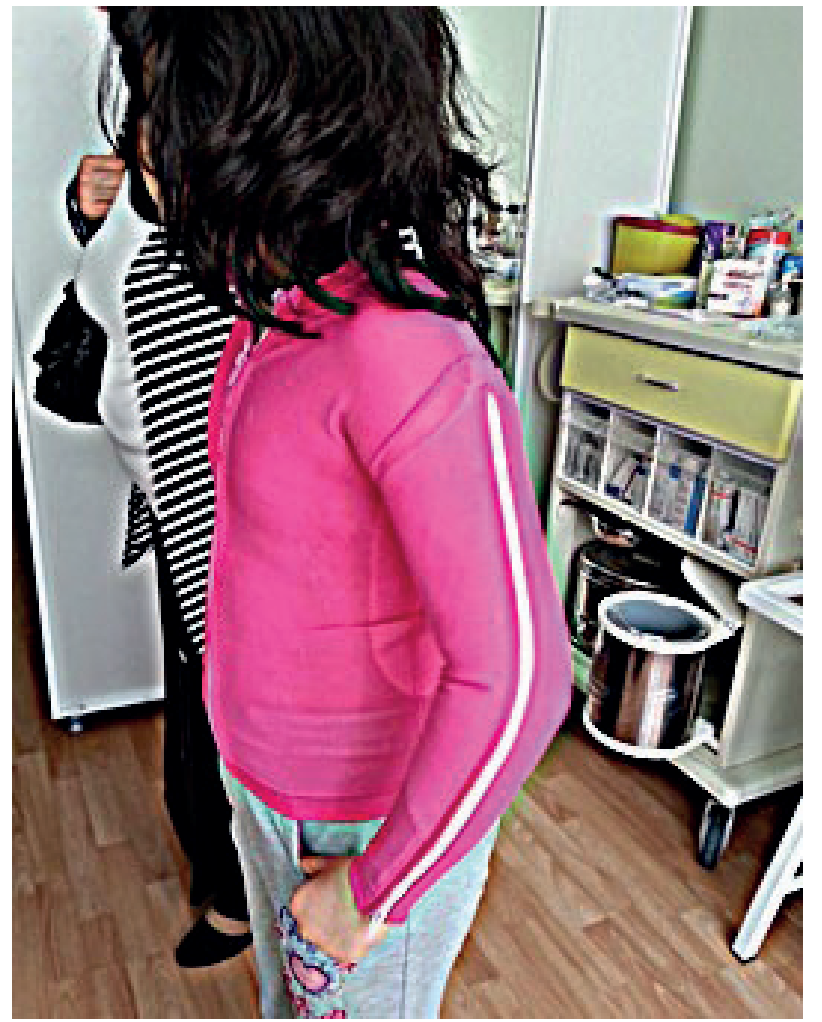

d) Bası giysisi.
Çalışmanın referans yanık merkezinde yapılmış olması TYY yüksekliğini (\% 17) ve mortaliteyi \% 8.9 açıklamaktadır. Araştırmacılar ülkelerin yanıkla ilgili ulusal sağlık politikalarına olan ihtiyacı vurgulamışlardır. Ülkemizde de 2012 yılında Sağlık Bakanlığı tarafından Yanık Tedavi Algoritması hazırlanmıștır (4). Çalışmamızda en sık yanık nedeni haşlanma olup çay en önemli etken olarak bulunmuştur. Ülkemizde kaynayan su ile çay hazırlandığı için çay ve su ile haşlanma ilk sırayı almaktadır. Bu alışkanlıktan toplumun vazgeçmesi pek mümkün görünmediğinden aileler bu konuda eğitilip bilinçlendirilmelidir. Alev ve temas yanıkları diğer çalışmalarda olduğu gibi sonraki siralarda yer almaktadır. Alev yanıkları parfüm ve jel ile oynama sırasında oluşmuş olup eğitim ile önlenebilecek etkenlerdir. Suriye'de bomba patlaması sonucu travmaya maruz kalan hastaya gerekli ilk müdahale ve resussitasyon yapılıp yanık merkezine transferi sağlanmıştır. Konya bölgesinde Hicri takvime göre Recep ayının ilk perşembe akşamı Şivlilik adıyla yapılan yöresel kutlamalarda çocukların yanan araba lastikleri üzerinden atlaması sirasinda oluşan alev ve kimyasal yanıklar görüldüğü bildirilmiştir (10). Literatürde bulunamamasına rağmen benzer kutlamalar Orta Asya ve Türk Dünyası'nda baharın gelişinin kutlandığı Nevruz bayramında görülmektedir. $\mathrm{Bu}$ tür kutlamarın içeriği değiştirilerek yanıklar önlenmelidir. Yanık tedavisinde topikal ilaçların kullanımı yanında yanık debridmanı ve greftlenmesi de önemli olup bu ünite ve merkezlerde görevli hekim ve yardımcı sağlık personelinin meslek içi eğitim kurslarına katılımı desteklenerek bilgilerini güncellemeleri sağlanmalıdır. Yanıklı hastalarda yara iyileşmesinin hılanması, katabolizmanın azaltılması, enfeksiyon azaltılması için beslenme desteği çok önemlidir (11). Yeterli kalori desteği kilo ve TYY'ne göre hesaplanıp sağlanmalıdır.

$\mathrm{Bu}$ hastalarda hipertrofik skar, kontraktür gelişimini önlemek, azaltmak için fizik tedavi yapılması sağlanmalı ve bası giysileri kullanılmalıdır. Atiyeh ve ark. yanıktan korunma programlarının yüksek risk gruplarını hedefleyerek dikkatle, 1srarla ve hassasiyetle yapılması gerektiğini belirtmişlerdir. Yeterli bütçeyle yerel, bölgesel ve üst merkezlerin koordinasyonunun sağlanarak ülke popülasyonlarına göre bunun ulusal programlar dahilinde yapılabileceğini ifade etmişler (12). Çocuklar kendilerini yanıktan koruyamayacak yaşta olduklarından ebeveynler gerekli önlem ve ilk yardım konusunda bilgilendirilmelidir. Yanık yönetiminde ulusal programlar gerekli ve önemli olup yanık tedavisinde görevli hekim ve hemşireler ilgili merkezlerde eğitim almalıdır. 


\section{KA $\boldsymbol{A} N \boldsymbol{A} K \boldsymbol{K} \boldsymbol{A} R$}

1. Phom Tam N, Gibran Nicole S,Heimbach David M. Evaluation of the burn wound: management decisions. In: Herndon David N editor. Total Burn Care 3rd edition Philadelphia 2007:119-26

2. Guzel A, Aksu B, Aylanç H, Duran R, Karasalihoglu S. Scalds in pediatric emergency department: a 5-year experience. J Burn Care Res. 2009;30(3):450-6.

3. Anlatici R, Ozerdem OR, Dalay C, Kesiktas E, Acartürk $S$, Seydaoglu G. A retrospective analysis of 1083 Turkish patients with serious burns. Part 2. Burn care, survival and mortality. Burns. 2002;28(3):239-43.

4. http://www.tkhk.gov.tr/DB/8/743_DB_8_yanik-tedavi-algoritmasi. TC Să̆lık Bakanlığ Türkiye Kamu Hastaneleri Kurumu Yanık Tedavi Algoritması, 2012.

5. Ciftçi I, Arslan K, Altunbaş Z, Kara F, Yilmaz H. Epidemiologic evaluation of patients with major burns and recommendations for burn prevention. Ulus Travma Acil Cerrahi Derg. 2012:18(2):105-10.
6. Anlatici R, Ozerdem OR, Dalay C, Kesiktas E, Acartürk $S$, Seydaoglu G. A retrospective analysis of 1083 Turkish patients with serious burns. Burns. 2002;28(3):231-7.

7. Karaveli TÇ, Karakaya AE, Karaveli A. Doğu Akdeniz bölgesindeki yanıkl çocukların epidemiyolojik özellikleri. Çocuk Cerrahisi Dergisi 30(2):95-101,2016.

8. Guzel A, Aksu B, Aylanç H, Duran R, Karasalihoglu S. Scalds in pediatric emergency department: a 5-year experience. J Burn Care Res. 2009;30(3):450-6.

9. Sakallioğlu AE, Başaran O, Tarim A, Türk E, Kut A, Haberal M. Burns in Turkish children and adolescents: nine years of experience. Burns. 2007;33(1):46-51.

10. Gündüz M, Çiftçi I, Sekmenli T. Shivlilik burns: injuries resulting from traditional celebrations. Int J Burns Trauma. 2015 Oct $12 ; 5(3): 75-8$

11. Ardahan E, Sarı HY. Pedivatrik yanık olgularında besin desteği. Çocuk Cerrahisi Dergisi 30(2):106-113,2016.

12. Atiyeh BS, Costagliola M, Hayek SN. Burn prevention mechanisms and outcomes: pitfalls, failures and successes. Burns. 2009;35(2):181-93. 